\title{
Impact Assessment of Workers on Short Term Exposure within the Recommended Permissible Noise Exposure Limit (85 - 90 dBA)
}

\author{
Orville M. Mancilla \\ De La Salle University, Dasmariñas, The Philippines \\ Email: ellivro18@gmail.com
}

How to cite this paper: Mancilla, O.M. (2021) Impact Assessment of Workers on Short Term Exposure within the Recommended Permissible Noise Exposure Limit (85 - 90 dBA). Open Access Library Journal, 8: e6770.

https://doi.org/10.4236/oalib.1106770

Received: October 8, 2021

Accepted: November 6, 2021

Published: November 9, 2021

Copyright $\odot 2021$ by author(s) and Open Access Library Inc.

This work is licensed under the Creative Commons Attribution International License (CC BY 4.0).

http://creativecommons.org/licenses/by/4.0/

\begin{abstract}
As occupational safety and health become a focus in developing third world countries like the Philippines, research, test, and measurement were given investment to improve the status of health and safety. This study sought to determine the effect of 85 to $90 \mathrm{dBA}$ exposure to workers in a controlled environment. Age, work experience, and gender were also assessed for possible correlation on the performance while exposed to different noise levels. One at a time, workers proceed to the audio isolation booth with observation window, controlled temperature, relative humidity, lightings, and noise level to complete three tasks namely abstract and logic test for 60 minutes, simplified mathematics test for 30 minutes, and set-up activity for 15 minutes. Each worker has to complete six sets of tests with a different continuous noise exposure level of 85 to $90 \mathrm{dBA}$. Observations of incidents inside the booth were also noted in the results. Workers perform best with a mean of $72 \%$ for 85 $\mathrm{dBA}$ in declining pattern to $38 \%$ performance for $90 \mathrm{dBA}$ noise exposure for the Abstract and logic test. The same pattern was observed for a simplified mathematics test with the mean of $86.80 \%$ for $85 \mathrm{~dB}$ dropping to $64 \%$ for 90 $\mathrm{dBA}$ exposure while the actual set-up activity obtained $65 \%$ mean for worker completion when exposed to $85 \mathrm{dBA}$ sliding to $35 \%$ for $90 \mathrm{dBA}$. In addition, the tallied health and safety issues raised by the workers and notes by the observers resulted in an increasing trend from $5 \%$ for $85 \mathrm{dBA}, 11 \%$ for 86 to 88 $\mathrm{dBA}, 26 \%$ for $89 \mathrm{dBA}$, and $37 \%$ for $90 \mathrm{dBA}$. On the other hand, Pearson correlation confirms the negative correlation of noise level to abstract and logic, simple mathematics, and practical assembly set-up while noise level has a positive correlation with Health and Safety issues. Overall, if the $90 \mathrm{dBA}$ noise level or higher is maintained in a specific workplace without any controls or interventions to lower down the noise level, the productivity and efficiency of workers will be low while their health and safety might be at risk.
\end{abstract}




\section{Subject Areas}

Environmental Sciences

\section{Keywords}

Noise, Noise Exposure, Permissible, Noise Exposure Limit, Noise Impact Assessment

\section{Introduction}

Occupational noise is considered as one of the most common widespread risk factors, with a strong evidence base linking it to an important health outcome (hearing loss) [1]. It was reported that about 600 million workers worldwide were exposed to occupational noise each year [2].

The Philippines as a developing country started the noise level standardization with the establishment of Occupational Safety and Health Standards in 1978 through the provision of Presidential Decree No. 442 of 1974, which is the Philippine Labor Code [3]. This includes the threshold limit values for noise current known as Permissible Noise Exposure Limit (PNEL) to serve as a baseline for industrial workplaces. PNEL refers to sound pressure that represents conditions under which it is believed that nearly all workers may be repeatedly exposed without adverse effects on their ability to hear and understand normal speech [4]. The Department of Labor and Employment (DOLE) under the Occupational Safety and Health Center (OSHC) set PNEL based on the number of hours of exposure. Currently, the PNEL for eight-hour work is $90 \mathrm{dBA}$. Since then, the PNEL of the Philippines remains at 90 dBA despite the Dec. 06, 2018 implementation of the Republic Act No. 11058 entitled "An Act Strengthening Compliance with Occupational Safety and Health Standards and Providing Penalties for Violations Thereof" [5].

As countries expand, the industry's noise exposure for workers also increases. Noise exposure in enclosed spaces such as the textile mill and steel plant ranges from 86 to $119 \mathrm{dBA}$ resulted in hearing losses of full-time workers in the Philippines [6]. In addition, noise exposure ranging from 80 to $99 \mathrm{dBA}$ results in to drop in productivity while increasing the issuance of disciplinary actions, absenteeism, and accidents among textile companies [7]. On the other hand, workers assign in an open space such as the traffic enforcers in the streets of Manila were exposed to noise but it does not exceed the current PNEL [8].

Although these studies determine the impact of noise on workers versus productivity and health and safety issues, all of these were conducted in an uncontrolled environment where multiple factors can affect the results. These factors might not only be the noise in the workplace but organizational management, economical factor, socio-psychological or physical factor [9].

Since data for developing countries are scarce, but available evidence suggests 
that average noise levels are well above the occupational level recommended in many developed nations [10]. These scenarios prompt the researcher to pursue a study regarding the impact of 90-dBA noise level on workers and find out whether $90 \mathrm{dBA}$ would be the safe level for workers. In addition, the researcher would like to check whether lower PNEL at $85 \mathrm{dBA}$ used by other countries such as the United States of America via the National Institute of Occupational Safety and Health (NIOSH) could affect the productivity of workers in an enclosed and controlled workspace.

A study supported by American Society of Heating, Refrigerating, and AirConditioning Engineers (ASHRAE) way back 2006 aims to determine whether varying noise exposure level affects worker's productivity. The test was composed of ten workers, five male and five female who were exposed to six different noise conditions while accomplishing different timed examinations inside an enclosed chamber, which resembles a typical office [11].

\section{Method}

A descriptive study design was used to collect data from the instrument, interviews, test results, and observations. A small business with a total of ten workers was chosen to participate on the study. The participants performed three tests while being exposed to six different noise levels with controlled illumination levels, relative humidity, and temperature. Collection and processing of data Pearson correlation will be, perform for the entire variable to know its relationship to the different noise levels [11].

\subsection{Interview}

A non-structured and informal interview was performed before the start of the experiment soliciting and noting down the personal information with emphasis on the age, working experience, and company residency of the workers. Orientation was conducted for all ten participants by explaining and describing the purpose and objectives of the study. Speaker was installed inside the room to introduce continuous noise and easily adjust the noise level. Sound Level Meter (SLM) was mounted to verify whether the noise level is maintained inside the booth.

\subsection{Abstract and Logic Examination}

This examination is composed of abstract and logical image sequences and patterns. There are six different sets of examinations, with 50 items each and it needs to be completed within 60 minutes. Pen, printed questionnaires, and a chair were provided inside the booth, proper sitting positions were not mandated to the workers. They were informed to sit in their most comfortable position. This examination aims to assess the worker's cognitive skills performance. [12]. It also aimed to verify at which noise level the worker performs the best [11]. 


\subsection{Simple Mathematics Examination}

Composed of simple mathematical questions that are all word problems. There were six different sets of tests with 25 items each that should be completed within 30 minutes. Pen, printed questionnaires, and chairs were provided inside the booth, proper sitting positions were not mandated to the workers. They were informed to sit in their most comfortable position. This examination aims to assess the worker's general cognitive skills such as working memory and to verify at which noise level the worker performs the best [12].

\subsection{Set-Up Examination}

Workers were required to finish ten set-ups within 15 minutes. To pass, the noise meter should be raised $1.2-1.5$ meters above the floor using a tripod. The noise meter should be "ON" and secured with a cable tie. In addition, this test includes disassembly of the set-up to re-set it up again. An Industrial Hygienist confirms the conformity of each completed set-up and marks it "passed".

\subsection{Health and Safety Data}

Data were collected on any health and safety issues observed by the Industrial Hygienist or reported by the participants while performing the test within the prescribed time.

\subsection{Controlled Environment}

The isolation booth can be adjusted to six controlled noise levels from $85 \mathrm{dBA}$, $86 \mathrm{dBA}, 87 \mathrm{dBA}, 88 \mathrm{dBA}, 89 \mathrm{dBA}$, and $90 \mathrm{dBA}$ adjusted using the portable speakers. Illumination is set at 250 lux, while the thermostat is set at 24 degrees Celsius indoor environmental temperature and relative humidity at $45 \%$. These variables were verified via calibrated tools such as room noise meter, lux meter, room thermometer, and hygrometer. The method assesses exposure at two noise levels ( $85-90$ and $>90 \mathrm{~dB}(\mathrm{~A})$ ), and by occupational category and economic subsector [1].

\subsection{Recording of Data}

The laboratory Industrial Hygienist performs the collection, checking, and verification of data from the test questionnaires, participant profile, scheduling, observations, environmental conditions, and interview of the workers.

\subsection{Data Analysis}

Data were analyzed using SPSS version 26 for descriptive statistics and Pearson correlation while complicated graphs and charts were created in Microsoft Excel version 2016.

\section{Results}

Presented below are the test results of each worker for the three examinations 
conducted to assess the impact of noise level on the performance of the workers.

Table 1 shows that employees exposed at $85 \mathrm{dBA}$ has a mean score of $72 \%$ correct answers for abstract and logic while it goes down to 59\% when employees are exposed at $86 \mathrm{dBA}$, a mean score of $57 \%$ for $87 \mathrm{dBA}, 52 \%$ for 88 $\mathrm{dBA}, 42 \%$ for $89 \mathrm{dBA}$ and $39 \%$ for $90 \mathrm{dBA}$.

As presented above, Table 2 shows that when employees are exposed to 85 dBA while answering simple mathematics problems a mean score of $72 \%$ was gained while it goes down to $81 \%$ when employees are exposed at $86 \mathrm{dBA}$, a mean score of $74 \%$ for $87 \mathrm{dBA}, 73 \%$ for $88 \mathrm{dBA}, 66 \%$ for $89 \mathrm{dBA}$ and $64 \%$ for 90 dBA.

Foregoing in Table 3 shows that when employees are exposed to $85 \mathrm{dBA}$ while doing set-up, a mean score of $81 \%$ was gained while it goes down to $77 \%$ when employees are exposed at $86 \mathrm{dBA}$, a mean score of $76 \%$ for $87 \mathrm{dBA}, 73 \%$ for 88 $\mathrm{dBA}, 69 \%$ for $89 \mathrm{dBA}$ and $67 \%$ for $90 \mathrm{dBA}$.

Aforementioned in Table 4, accidents and health issues occur nineteen times in total with seven related to health and 12 for safety (accidents) while inside the isolation booth.

Table 1. Abstract and logic percentage test results.

\begin{tabular}{cccccccccccc}
\hline dBA & P1 & P2 & P3 & P4 & P5 & P6 & P7 & P8 & P9 & P10 & Mean \\
\hline $\mathbf{8 5}$ & 96 & 48 & 24 & 80 & 60 & 94 & 66 & 80 & 86 & 86 & $\mathbf{7 2}$ \\
$\mathbf{8 6}$ & 90 & 32 & 22 & 70 & 50 & 60 & 62 & 58 & 66 & 76 & $\mathbf{5 9}$ \\
$\mathbf{8 7}$ & 82 & 30 & 30 & 66 & 50 & 58 & 58 & 58 & 62 & 76 & $\mathbf{5 7}$ \\
$\mathbf{8 8}$ & 72 & 66 & 28 & 50 & 46 & 54 & 56 & 60 & 56 & 36 & $\mathbf{5 2}$ \\
$\mathbf{8 9}$ & 58 & 22 & 26 & 42 & 40 & 50 & 40 & 50 & 54 & 36 & $\mathbf{4 2}$ \\
$\mathbf{9 0}$ & 48 & 44 & 26 & 30 & 38 & 40 & 36 & 42 & 50 & 32 & $\mathbf{3 9}$ \\
\hline
\end{tabular}

${ }^{*}$ Values in percentage (\%).

Table 2. Simple mathematics percentage test results.

\begin{tabular}{cccccccccccc}
\hline dBA & P1 & P2 & P3 & P4 & P5 & P6 & P7 & P8 & P9 & P10 & Mean \\
\hline $\mathbf{8 5}$ & 100 & 80 & 60 & 88 & 80 & 92 & 92 & 92 & 88 & 96 & $\mathbf{8 7}$ \\
$\mathbf{8 6}$ & 84 & 100 & 60 & 84 & 60 & 88 & 92 & 88 & 72 & 80 & $\mathbf{8 1}$ \\
$\mathbf{8 7}$ & 88 & 100 & 60 & 72 & 56 & 80 & 88 & 80 & 60 & 60 & $\mathbf{7 4}$ \\
$\mathbf{8 8}$ & 88 & 96 & 60 & 72 & 60 & 80 & 60 & 80 & 76 & 60 & $\mathbf{7 3}$ \\
$\mathbf{8 9}$ & 92 & 96 & 60 & 60 & 48 & 76 & 60 & 52 & 60 & 60 & $\mathbf{6 6}$ \\
$\mathbf{9 0}$ & 96 & 96 & 60 & 60 & 40 & 60 & 60 & 76 & 40 & 52 & $\mathbf{6 4}$ \\
\hline
\end{tabular}

${ }^{\star}$ Values in percentage (\%). 
Table 3. Actual set-up productivity percentage results.

\begin{tabular}{cccccccccccc}
\hline dBA & P1 & P2 & P3 & P4 & P5 & P6 & P7 & P8 & P9 & P10 & Mean \\
\hline $\mathbf{8 5}$ & 80 & 80 & 80 & 80 & 90 & 80 & 80 & 80 & 80 & 80 & $\mathbf{8 1}$ \\
$\mathbf{8 6}$ & 80 & 80 & 80 & 80 & 90 & 70 & 70 & 70 & 7 & 80 & 77 \\
$\mathbf{8 7}$ & 80 & 80 & 80 & 70 & 90 & 70 & 70 & 70 & 70 & 80 & $\mathbf{7 6}$ \\
$\mathbf{8 8}$ & 80 & 80 & 70 & 70 & 80 & 80 & 70 & 70 & 60 & 70 & $\mathbf{7 3}$ \\
$\mathbf{8 9}$ & 70 & 70 & 70 & 70 & 80 & 70 & 70 & 70 & 60 & 60 & $\mathbf{6 9}$ \\
$\mathbf{9 0}$ & 70 & 60 & 70 & 70 & 70 & 70 & 70 & 70 & 60 & 60 & $\mathbf{6 7}$ \\
\hline
\end{tabular}

*Values in percentage (\%).

Table 4. Health and safety summary results.

\begin{tabular}{ccccccc}
\hline \multirow{2}{*}{ dBA } & \multicolumn{3}{c}{ SAFETY } & \multicolumn{3}{c}{ HEALTH } \\
\cline { 2 - 6 } & Test 1 & Test 2 & Test 3 & Test 1 & Test 2 & Test 3 \\
\hline $\mathbf{8 5}$ & & & 1 & & & \\
86 & 1 & & 1 & 1 & \\
$\mathbf{8 7}$ & & 1 & 1 & 1 & \\
$\mathbf{8 8}$ & 1 & & 1 & & \\
$\mathbf{8 9}$ & 1 & 1 & 1 & & 2 & 2 \\
90 & 3 & 2 & 7 & 0 & 4 & 3 \\
Total per test & & 12 & & & 7 & \\
Total & & & & & & \\
\hline
\end{tabular}

${ }^{\star}$ Issues are tallied per total number.

\section{Discussion}

Figure 1 test result shows no direct relationship to the age of the workers since all workers of the same age such as SP1 and SP3 at age 28 rank first and lasts which is nine places away from one another. SP5 and SP6 at age 34 rank eighth and third with five ranking difference from one another, SP9, and SP10 at age 39 ranks second and fifth, which is three places away from one another as per the rankings. All the personnel of the same age has different means, which fluctuate the results up and down which results in an unpredictable bar graph. As for the years of experience (represented by the brown line) when correlated with the examination results. It was identified that there is no clear pattern of whether personnel with longer experience performs better than the less experienced ones or vice versa, as SP1 having two-year experience received a mean of 74.33 which ranks first as the best performer while SP9 which has nine years of experience receives 62.33 and ranked as a second-highest score. Since they rank first and second, this gives the experience correlation a fluctuating or unpredicted result. In addition, SP1 and SP6 with two years' experience, which is the most inexperienced among the group, rank first and third respectively while SP10 with the 


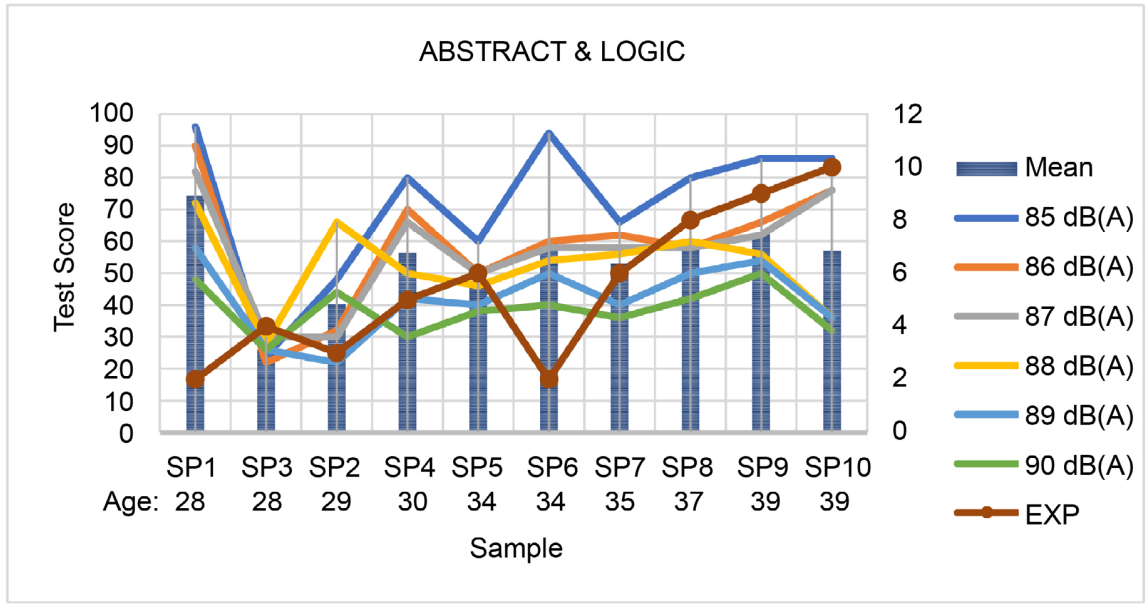

Figure 1. Abstract \& logic productivity correlated to age, experience and mean.

most experience at ten years ranks fifth which is located in the middle of the group. This gives an unpredictable result for the sampled group.

Figure 2 test results show no direct relationship to the age of the workers though SP9 and SP10 at age 39 rank eighth and seventh respectively, SP1 and SP3 at age 28 rank second and ninth respectively which are seven places away from one another, while SP5 and SP6 at age 34 rank tenth and third which are seven places away from one another also. This resulted in an unpredictable bar graph. As for the experience correlated with the examination results, it is identifiable that there is no clear pattern of whether personnel with longer experience performs better than the fewer experience ones or vice versa. SP1 and SP6 with two years' experience, which is the most inexperienced among the group, ranks second and tenth respectively while SP10 with the most experience at ten years ranks seventh. This gives an unpredictable result for the sampled group.

Figure 3 results show no direct relationship to the age of the workers since all workers of the same age, such as SP1 and SP3 at age 28, ranks second and third which is one place away from one another; SP5 and SP6 at age 34 rank first and fifth with four places away from one another and SP9 and SP10 at age 39 ranks tenth and seventh with three places away from one another as per the rankings. All the personnel of the same age has different means, which fluctuate the results up and down which results in an unpredictable bar graph.

Likewise, experience correlated with the examination results; it is identifiable that there is no clear pattern whether personnel with longer experience performs better than the less experienced ones or vice versa. SP1 and SP6 with two years' experience, which is the most inexperienced among the group, rank second and fifth respectively. In addition, SP5 and SP7, which have six years of experience, rank first and seventh respectively, that is six places apart from one another, while SP10 with the most experience at ten years ranks seventh. This gives an unpredictable result for the sampled group.

Figure 4 shows Health and Safety issues raise are back ached and stress that was noted for four participants of the ages $28,30,34$, and 35 respectively (all 


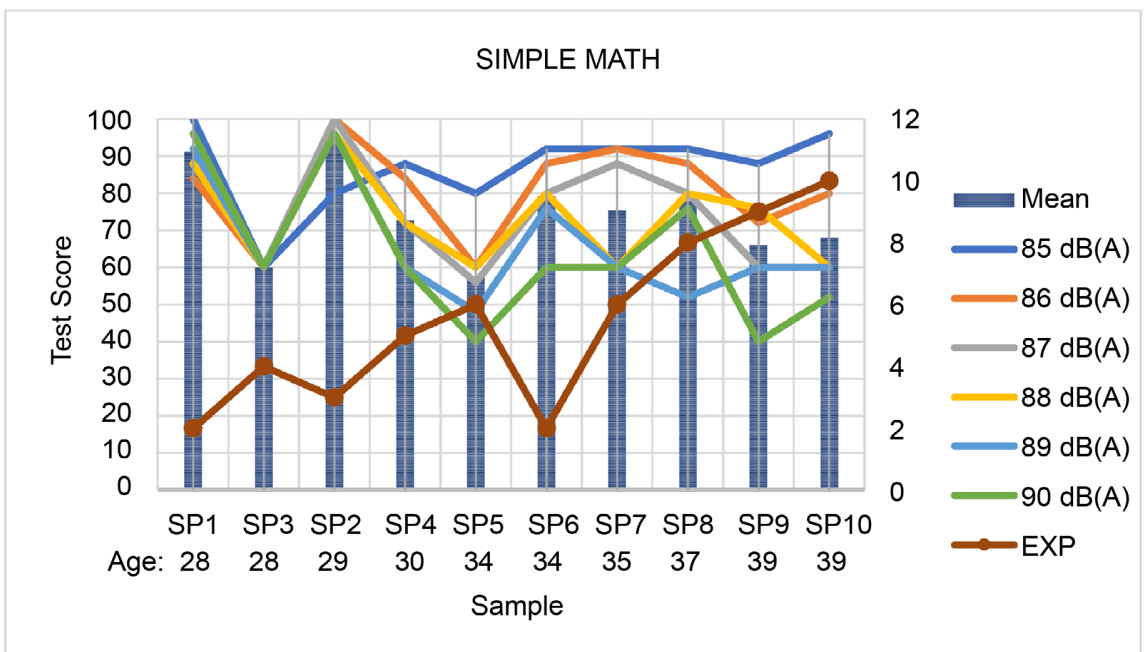

Figure 2. Simple mathematics correlated to age, experience and mean.

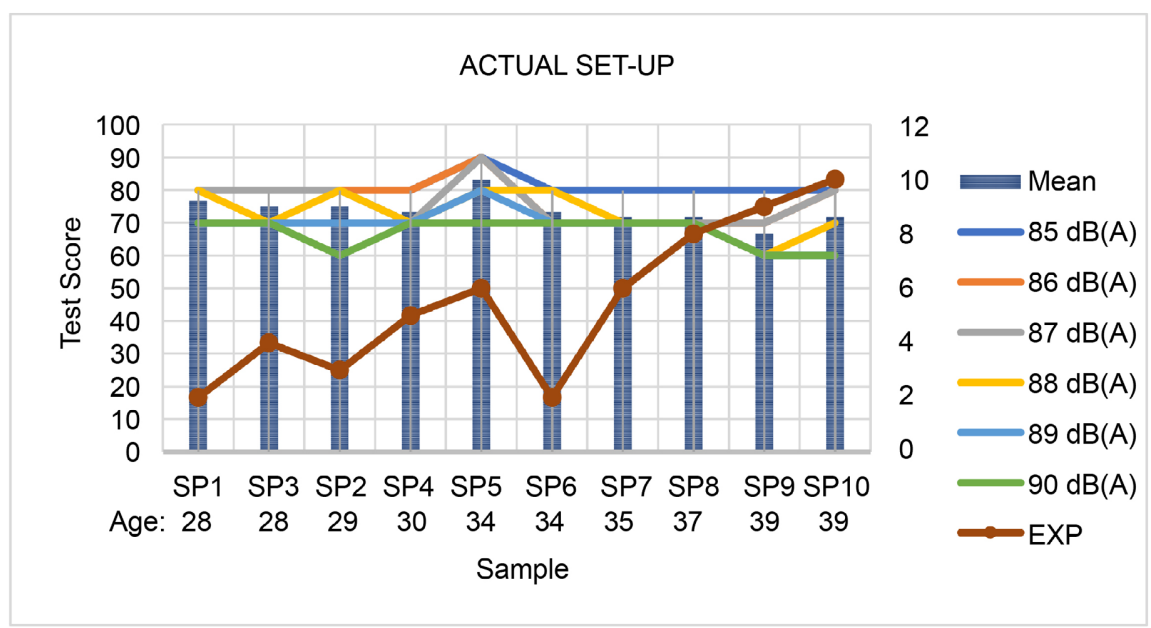

Figure 3. Actual set-up correlated to age, experience and mean.

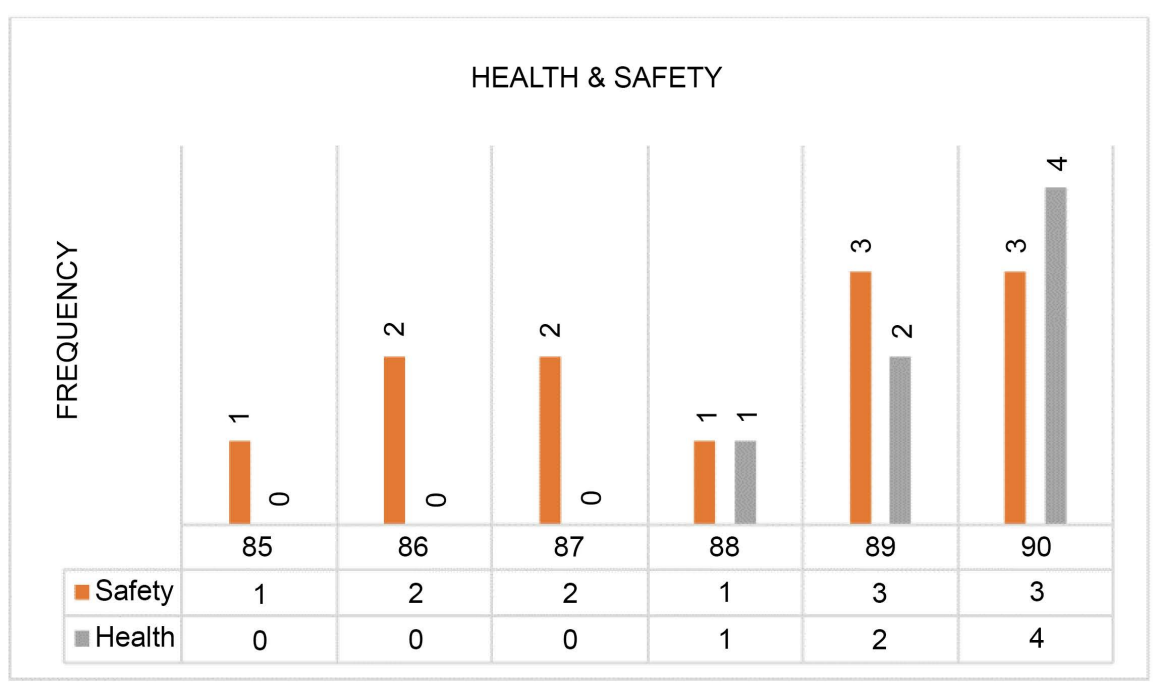

Figure 4. Health and safety issues. 
male) during the after-exposure examination. On the other hand, a falling object, such as a pen, tape measure, and tripod was noted as the source of safety issues.

Figure 5 shows that female examination results are higher than males for simple mathematics and actual noise measurement. As such, male examination results are higher for the abstract and logic examination. Although this result has a non-proportioned number of male and female participants, having eight males and two females.

Figure 6 reveals that as the noise level increases from $85 \mathrm{dBA}$ to $90 \mathrm{dBA}$, the three mean scores of the samples decrease. Hence, the increasing noise level serves as a hindrance that affects the test results of the workers. Notably, the simple mathematics output has the highest results while the actual set-up output results have the lowest outcome.

Three tests were conducted for 10 employees to find the highest productivity level, lowest incident rates, and minimal possible health stress or issues when

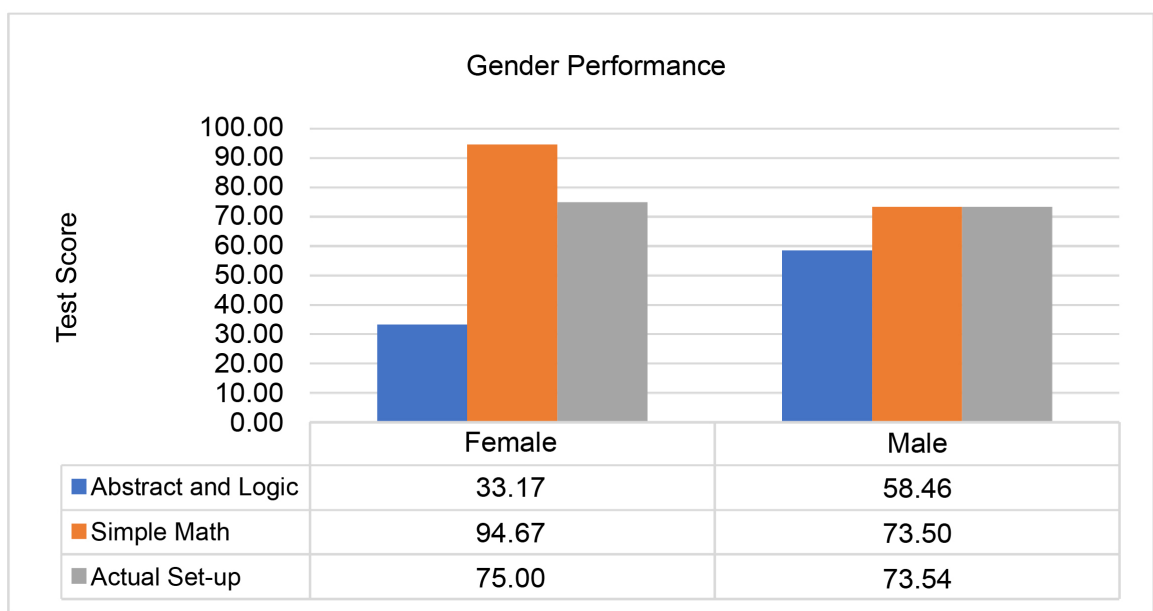

Figure 5. Gender performance comparison.

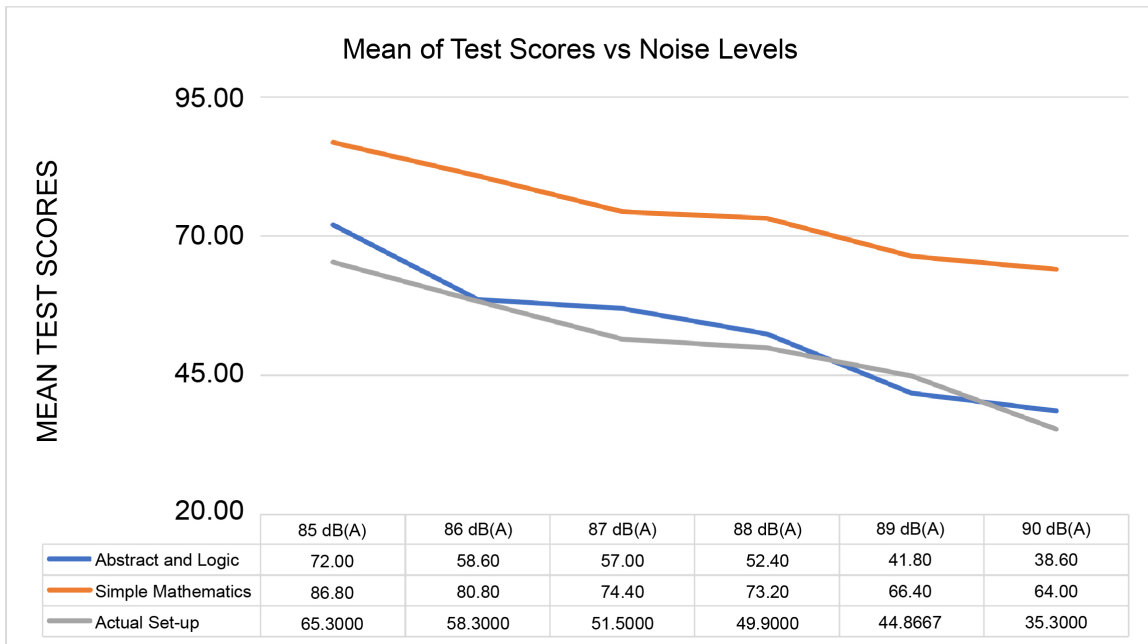

Figure 6. Mean of test scores vs noise levels. 
they are exposed to $85,86,87,88,89$, and $90 \mathrm{dBA}$ for 1.75 hours in total. These tests challenged the current $90 \mathrm{dBA}$ standard set by the Philippine government under DOLE-OSHC. In the abstract and logic examination, it is evident that 85 $\mathrm{dBA}$ produced the highest results in an average of all the ten participants with a $72 \%$ score output. Nevertheless, $8 / 10$ got the highest result in the said noise level exposure. Two participants had managed to perform their best on higher noise exposure. This test also shows that $80 \%$ of participants can identify photos and shapes differences including sequential order of patterns with $60 \%$ precision. For the simple mathematics examination, $90 \%$ secured the highest score while exposed to $85 \mathrm{dBA}$ noise. This means that $9 / 10$ workers can perform rational thinking for solving mathematical word problems. As noise increases the scores on the exam dropped from $87 \%$ to $64 \%$. The test determines the efficiency of an actual setup, which provides accurate productivity for the test. And based on the results, taking into consideration the noise exposure, $100 \%$ performed at their best within the $85 \mathrm{dBA}$ exposure.

An additional observation was also taken into consideration such as health and safety issues; this is minimal for the test as the room is small while the required movements are few to cause accidents. However, the summary of the Health and Safety observation also resulted in higher disturbance to the examinees during higher noise exposure.

Aforementioned in Table 5, the Pearson correlation results for noise levels correlated with the dependent variables. Results show that the Noise Level has a moderate negative Pearson correlation with Abstract and Logic examination at -0.571 and is significant at 0.000 . This reveals that the participant's mental workload and visual or auditory attention is significantly reduced when exposed to the higher noise level [13].

While Noise level correlated with the Simple Mathematics examination has moderate negative Pearson correlation at -0.475 and is significant at 0.000 . This means that a high background noise level ( $\geq 85 \mathrm{dBA}$ ) negatively affects the performance of workers when it comes to their mathematics skills and comprehension [14].

Table 5. Pearson correlation for noise level \& dependent variables.

\begin{tabular}{ccc}
\hline \multirow{2}{*}{ Dependent Variables } & \multicolumn{2}{c}{ Noise Level } \\
\cline { 2 - 3 } & Pearson Correlation & Sig. (2-tailed) \\
\hline Abstract and Logic & $-0.571^{* *}$ & 0.000 \\
Simple Mathematics & $-0.475^{* *}$ & 0.000 \\
Practical Assembly & $-0.646^{* *}$ & 0.000 \\
Health Issues & $0.410^{* *}$ & 0.001 \\
Safety Issue & 0.133 & 0.310 \\
\hline
\end{tabular}

${ }^{*}$ Correlation is significant at the 0.01 level (2-tailed). 
Noise Level correlated with Practical Assembly or Set-up has a high negative Pearson correlation at -0.646 and is significant at 0.000 . This implies that noise has an inversely proportional relationship with workers' productivity of set-up assembly wherein, the higher the noise level the lower the number of qualified assemblies completed [15].

In addition, Noise Level correlated with Health Issues has a moderate positive Pearson correlation at 0.410 and is significant at 0.001 . This means that workers exposed to higher noise levels ( $\geq 85 \mathrm{dBA}$ ) may develop health issues [16], although further study needs to be conducted to identify what are the health issues that may occur.

Lastly, Noise Level correlated with Safety Issues (accidents) has a negligible positive Pearson correlation at 0.133 and is not significant at 0.310 .

\section{Conclusion}

This study found out that there is a significant correlational impact between the tested noise levels ( $85-90 \mathrm{dBA}$ ) within a short-term exposure versus the ability of workers to identify visual patterns, comprehend and solve simple mathematics problems, and complete an assembly or set-up. Wherein, workers performance decrease as noise level increase. Subsequently, safety or the occurrence of accident was not significant however, noise level has also affected the workers' health as issues were raised during the test but further study needs to be perform to investigate whether noise affect the health of workers and what health issue arise within the short term exposure.

\section{Acknowledgements}

A heartfelt thanks to the best advisers, namely, Engr. Rene Rubio and Engr. Carol Jazmine Dizon demonstrates their expertise in guiding the proponent concerning technical, grammar, and statistical aspects of the study. These persons are the key to drafting and finalizing the study.

\section{Conflicts of Interest}

The author declares no conflicts of interest.

\section{References}

[1] Barrientos, M.C., Lendrum, D.C. and Kyle, S. (2004) Occupational Noise: Assessing the Burden of Disease from Work-Related Hearing Impairment at National and Local Levels. WHO Environmental Burden of Disease Series No. 9, World Health Organization.

[2] Daniel, E. (2007) Noise and Hearing Loss: A Review. Journal of School Health, 77, 225-231. https://doi.org/10.1111/j.1746-1561.2007.00197.x

[3] International Labor Organization (ILO) (2013). https://www.ilo.org/dyn/legosh/en/f?p=14100:1100:0::NO:1100:P1100 ISO CODE3 „P1100 SUBCODE CODE,P1100 YEAR:PHL,2013:NO

[4] Occupational Safety and Health Center (OSHC) (2019) Occupational Safety and 
Health Standards (As Amended, 1989). Occupational Safety and Health Center, Quezon.

[5] Bello, S.I. (2018) Department of Labor and Employment-Occupational Safety and Health Center.

https://oshc.dole.gov.ph/implementing-rules-and-regulation-of-ra-11058/

[6] Jose, F. (1976) A Study of the Noise Hazard in Selected Industries in the Philippines. The Southeast Asian Journal of Tropical Medicine and Public Health, 1, 106111.

[7] Noweir, M.H. (1984) Noise Exposure as Related to Productivity, Disciplinary Actions, Absenteeism, and Accidents among Textile Workers. Journal of Safety Research, 15, 163-174. https://doi.org/10.1016/0022-4375(84)90048-3

[8] Dulay, L.E.R., Galvan, M.D.K.P., Puyaoan, R J.M., Hernandez, S.A.A.Y., Natanauan, N.S. and Hernandez, P.M. (2018) Occupational Noise Exposure of Traffic Enforcers in Selected Streets in the City of Manila. Acta Medica Philippina, 52, 261-267.

[9] Kazaz, A., Ulubeyli, S., Acikara, T. and Er, B. (2016) Factors Affecting Labor Productivity: Perspectives of Craft Workers. Procedia Engineering, 164, 28-34. https://doi.org/10.1016/j.proeng.2016.11.588

[10] Suter, A. (2000) The Noise Manual. 5th Edition, American Industrial Hygiene Association, Fairfax.

[11] Errett, J., Bowden, E.E., Choiniere, M. and Wang, L.M. (2006) Effects of Noise on Productivity: Does Performance Decrease over Time? Architectural Engineering Conference (AEI) 2006, Omaha, 29 March-1 April 2006. https://doi.org/10.1061/40798(190)18

[12] Andersson, U. (2007) The Contribution of Working Memory to Children's Mathematical Word Problem Solving. Applied Cognitive Psychology, 21, 1201-1216. https://doi.org/10.1002/acp.1317

[13] Jafari, M.J., Khosrowabadi, R., Khodakarim, S. and Mohammadian, F. (2019) The Effect of Noise Exposure on Cognitive Performance and Brain Activity Patterns. Open Access Macedonian Journal of Medical Sciences, 7, 2924-2931.

[14] Caviola, S., Visentin, C., Borella, E., Mammarella, I. and Prodi, N. (2021) Out of the Noise: Effects of Sound Environment on Maths Performance in Middle-School Students. Journal of Environmental Psychology, 73, Article ID: 101552. https://doi.org/10.1016/j.jenvp.2021.101552

[15] Khajenasiri, F., Zamanian, A. and Zamanian, Z. (2016) The Effect of Exposure to High Noise Levels on the Performance and Rate of Error in Manual Activities. Electronic Physician, 8, 2088-2093. https://doi.org/10.19082/2088

[16] Li, X.D., Song, Z.Y., Wang, T., Zheng, Y. and Ning, X. (2016) Health Impacts of Construction Noise on Workers: A Quantitative Assessment Model Based on Exposure Measurement. Journal of Cleaner Production, 135, 721-731. https://doi.org/10.1016/j.jclepro.2016.06.100 